Serrano, B., F. Piérola, I., Bravo, J. \& Baselga, J. (2003). Effect of the morphology of two phase polymer blends on glass transition temperature.

Journal of Materials Processing Technology, 141 (1), pp. 123-126.

DOI: $10.1016 / \mathrm{S} 0924-0136(03) 00245-0$

(C) Elsevier, 2003

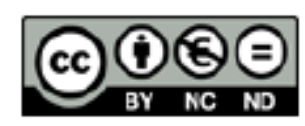

This work is licensed under a Creative Commons Attribution-NonCommercialNoDerivatives 4.0 International License. 


\title{
Effect of the morphology of two phase polymer blends on glass transition temperature
}

\author{
B. Serrano ${ }^{\text {a,* }}$, I.F. Pierola ${ }^{\mathrm{b}}$, J. Bravo ${ }^{\mathrm{a}}$, J. Baselga ${ }^{\mathrm{a}}$ \\ ${ }^{a}$ Dpto. de Ciencia de los Materiales, Universidad Carlos III de Madrid, 28911 Leganés, Spain \\ ${ }^{\mathrm{b}}$ Dpto. de CC y TT Fisicoquímicas, Universidad a Distancia (UNED), 2804 Madrid, Spain
}

\begin{abstract}
Blends of poly(cyclohexylmethacrylate), PChMA, with poly(vinylacetate), PVAc, were prepared by casting THF and chloroform solutions. A calorimetric and morphologic study was performed. Differential scanning calorimetry investigations of the blends show two glass transition temperature that give evidence of inmiscibility. For polymer less flexible (PChMA)

was observed an enhancement of $T_{\mathrm{g}}$ by $20^{\circ} \mathrm{C}$ approximately in blends of PVAc-rich composition. Epifluorescence microscopy, using PChMA labelled by copolymerization pirenyl-methylmethacrylate, Py, shows also phase separation providing imaging of the distribution of PChMA in the different domains and in the matrix. Blends containing $80 \% \mathrm{w} / \mathrm{w}$ PChMA show a bicontinuous primary morphology suggesting a spinodal phase separation mechanism. The 50 and $20 \%$ PChMA samples show morphologies composed of PChMA-rich domains in a matrix composed by PVAc mainly. Blends with domain-matrix morphology present a higher $T_{\mathrm{g}}$ than pure homopolymer more rigid (PChMA) due to packing in microphases in matrix of more flexible polymer (PVAc).
\end{abstract}

Keywords

Epifluorescence microscopy; Polymer blends; Blend morphology; Glass transition temperature

\section{Introduction}

Polymer blends formed with homopolymers are interesting for several reasons. First of all, because they allow the optimization of some properties compared with the isolated homopolymers, and therefore is an economic way to create materials with desired properties. In the second place, mixing of polymer is interesting from a theoretical point of view. It is of great importance to know the structure and its influence on blend properties.

When the blends are not miscible, their properties are influenced by the morphology of the segregated domains and by the effect of surface energy and interfacial composition. Of all the properties of phase-separated polymer blends, the interface between adjacent phases is the least understood. The limited amount of information available about polymer-polymer interfaces is a direct consequence of the fact that there are few techniques that allow one study directly $[1,2]$. The theory of polymer blends describes the polymer-polymer interaction between individual domains in terms of the interaction energy density and the dimension of the polymer coil [3].

\footnotetext{
* Corresponding author.
}

Several indirect techniques are available for these studies, including some microscopy techniques such as electron scanning and transmission [2], infrared spectroscopy [4], Xray microanalyses [5] and scattering techniques and conventional methods such as mechanical, rheological, and measurements of interfacial tension [6]. In addition, fluorescence techniques are useful in studies of polymer compatibility [7]. This technique requires an intrinsically fluorescent polymer or the incorporation of fluorescent probes, either labelled to polymer or added to mixture which are able to selectively dye one phase of the polymer blends $[8,9]$. Other methods are based on the measurement of the nonradiative energy transfer that depends on the distance between both fluorophores (guest in different domain), and therefore on the interpenetrating in the interface between the individual domain [10-12]. Epifluorescence microscopy (EFM) and fluorescence microspectroscopy were also employed to study the domains incompatible in blends with poly(vinyl acetate) $[11,13,14]$. However, the more sensitive technique is that the smaller domain it can detect. So, the level of homogeneity depends on the technique used in the investigation [15].

On the other hand, the effect of surface energy between different domain can be also analysed by variation of $T_{\mathrm{g}}$ using differential scanning calorimeter (DSC). When the highly flexible polymer allows that rigid polymer packs in 
Table 1

Charazterization of samples: intrinsic viscosity $([\eta])$, viscosity-average molecular weight $\left(M_{\mathrm{v}}\right)$, glass transition temperature $\left(T_{\mathrm{g}}\right)$, and molar fraction of chromophore in labelled PChMA samples $\left(F_{\mathrm{c}}\right)$

\begin{tabular}{llccl} 
& {$[\eta](\mathrm{dl} / \mathrm{g})$} & $M_{\mathrm{v}} \times 10^{-3}$ & $T_{\mathrm{g}}\left({ }^{\circ} \mathrm{C}\right)$ & $F_{\mathrm{c}}(\mathrm{mol} \%)$ \\
\hline PVAc & 0.54 & 90 & 41 & - \\
PChMA-Py & 0.34 & 102 & 82 & 0.20 \\
\hline
\end{tabular}

microphases, the last polymer forms more compactly than in a pure homopolymer and a growth in $T_{\mathrm{g}}$ of the rigid polymer is observed [16]. In this paper we use both techniques, DSC and EFM with the aim of studying the effect of morphology of two phase polymer blend of poly(cyclohexyl methacrylate)/poly(vinyl acetate), PChMA/PVAc, on glass transition temperature.

\section{Experimental section}

Poly(cyclohexyl methacrylate), PChMA, sample was obtained by radical polymerization and labelled with (1pirenyl-methyl)methacrylate (Py) (polyscience) as reported previously $[13,14]$. PVAc was purchased from polysciences and used without any further purification. Intrinsic viscosities were measured at $30{ }^{\circ} \mathrm{C}$ in an automatic Schot Viscometer, and the corresponding molecular weights were calculated with the viscosimetric equation of the homopolymer taken from Ref. [17]. The chromophore molar fraction in the copolymers, $F_{\mathrm{c}}$ was calculated by spectrophotometry (Perkin-Elmer Lambda 4). The glass transition temperatures were measured with a DSC (Perkin-Elmer DSC-7) equipped with an intracooler. All $T_{\mathrm{g}}$ measurements were made at a scan rate of $20^{\circ} \mathrm{C} \mathrm{min}^{-1}$ and the $T_{\mathrm{g}}$ values were taken as the midpoint between the liquid and the glassy lines. Table 1 summarizes the characteristics of the PChMA-dye and PVAc employed in this work.

Films of polymer blends (PChMA/PVAc) were prepared by mixing of three different compositions (20/80, 50/50 and 80/20) from both THF and chloroform $\left(\mathrm{Cl}_{3} \mathrm{CH}\right)$ casting at room temperature. Then, the resulting polymer solution was poured into a silanized flat glass and held at room tempera- ture for $48 \mathrm{~h}$ followed by residual solvent removal in a vacuum oven for $48 \mathrm{~h}$. EFM with imaging detection were measured on a Nikon Labophot microscope equipped with a CCD camera, and a $100 \mathrm{~W} \mathrm{Hg}$ arc lamp, filtered to transmit in the range 330-380. The emission was separated from the excitation beam by a dichroic mirror $\left(\lambda_{\mathrm{ex}}<400 \mathrm{~nm}\right)$, and a barrier filter $\left(\lambda_{\mathrm{em}}<420 \mathrm{~nm}\right)$.

Measurements of the glass transition temperatures of polymer blends were performed in a Perkin-Elmer DSC7. Samples were prepared by casting from both THF and $\mathrm{Cl}_{3} \mathrm{CH}$. Samples were dried under vacuum at $50{ }^{\circ} \mathrm{C}$ for 4 days and preheated at $150{ }^{\circ} \mathrm{C}$ for $10 \mathrm{~min}$ prior to experiment. Measurements were made at scan rate a $20^{\circ} \mathrm{C} \mathrm{min}^{-1}$.

\section{Results and discussion}

Fig. 1 shows the EFM optical micrographs of the castTHF PChMA-Py/PVAc blend samples of three compositions, 20/80, 50/50 and 80/20. Especially for the 20 and 50\% PChMA compositions, the micrographs show a dispersed morphology with fluorescence domains formed by PChMA mainly and dark matrix formed by PVAc. The fluorescent domain are distributed over the matrix in two size scales: large domain, in the range of $100 \mu \mathrm{m}$; and much smaller domains, of about $1 \mu \mathrm{m}$. When an additional lateral illumination is using, the small domain are crater-like void really, and they are on the air-polymer interface. Nevertheless, for $80 \%$ PChMA composition a bicontinuous primary morphology is observed showing a complex interconnected morphology. When the magnification is increased, a secondary phase-in-phase morphology is observed with small dark domain distributed in PChMA-rich region and small fluorescent PChMA domain throughout dark region (PVAcrich).

Films cast from $\mathrm{Cl}_{3} \mathrm{CH}$ are more homogeneous than from cast-THF. Fig. 2 shows the epifluorescence micrographs of three composition studied. The $20 \%$ PChMA composition is homogeneous-like blend when an objective of $10 \times$ is using. Nevertheless when the magnification is increased $(40 \times)$, small fluorescence domains distributed in matrix are observed. The 50/50 sample shows a phase-separated
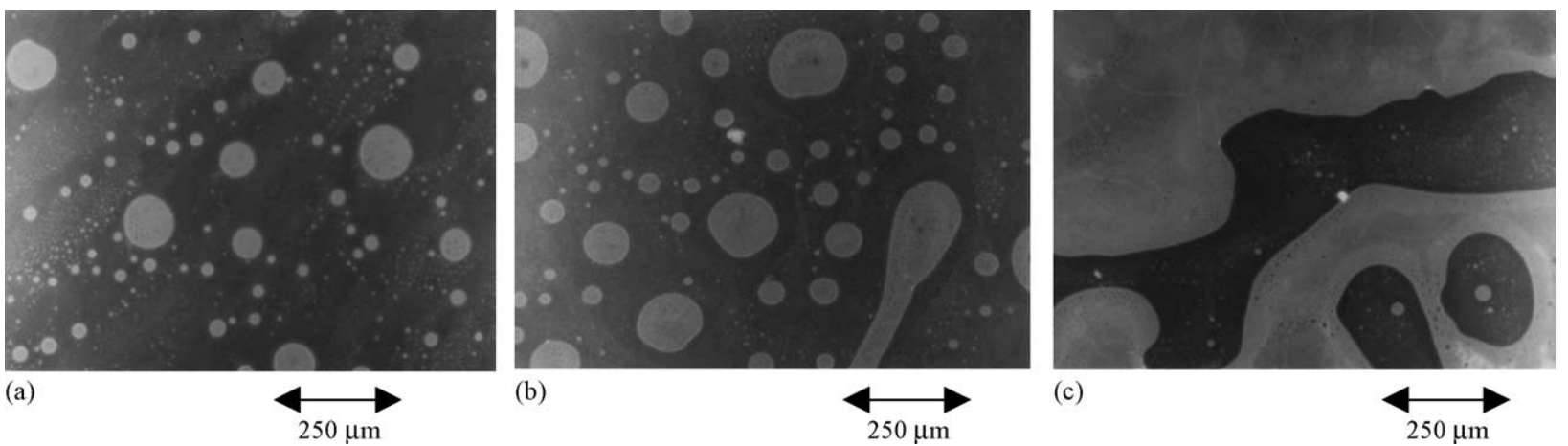

Fig. 1. Epifluorescence micrograph (objective of 10×) of PChMA-Py/PVAc blends with composition: (a) 20/80, (b) 50/50 and (c) 80/20 cast from THF. 

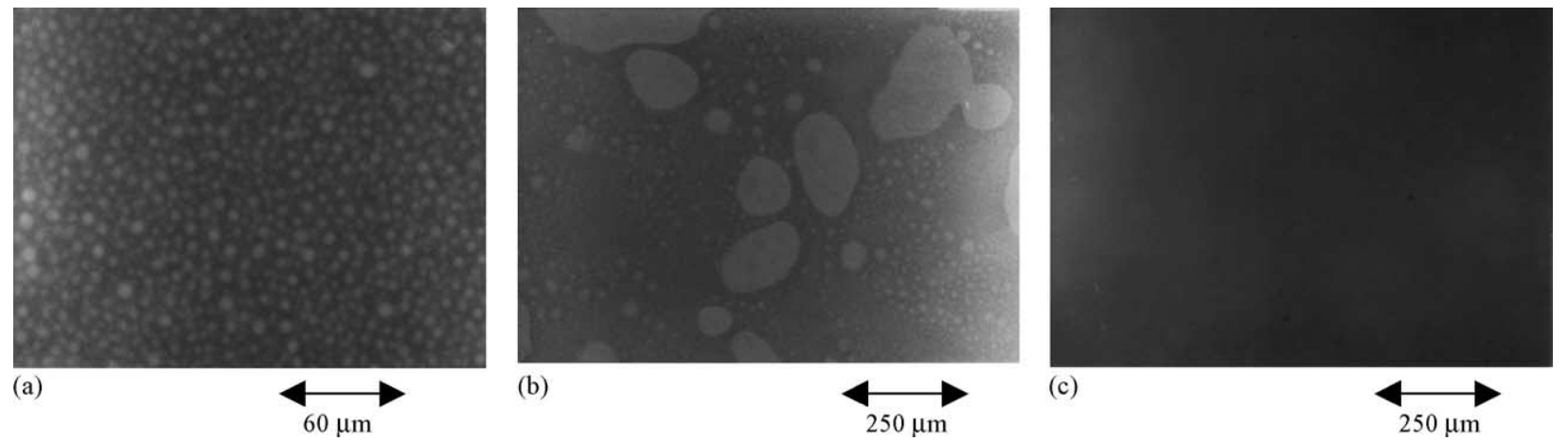

Fig. 2. Epifluorescence micrograph of PChMA-Py/PVAc blends with composition: (a) 20/80 (40×), (b) 50/50 (10×) and (c) $80 / 20(10 \times)$ cast from Cl ${ }_{3} \mathrm{CH}$.

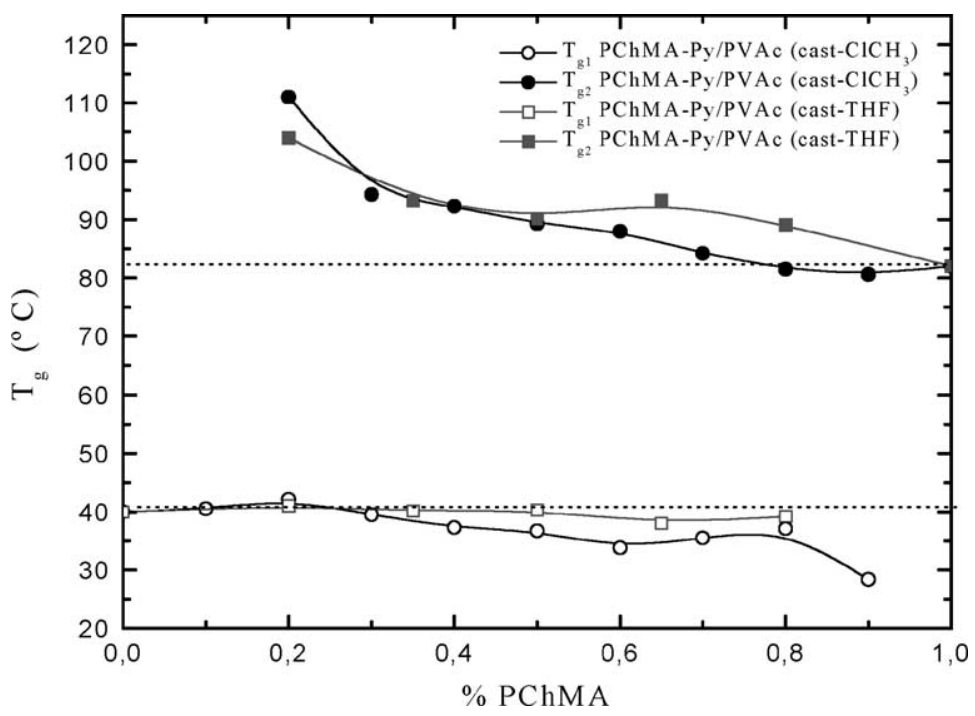

Fig. 3. Second run glass transition temperatures of PChMA-Py/PVAc blends cast from THF (circle) and $\mathrm{Cl}_{3} \mathrm{CH}$ (square).

domain-matrix like 20/80 and 50/50 films from cast-THF, but now the matrix is slightly fluorescent. While the darkness surrounding of fluorescent domains of PChMA in films from cast-THF means that the matrix is pure PVAc, films from cast- $\mathrm{Cl}_{3} \mathrm{CH}$ with a matrix slightly coloured, means that it is constituted by blend of the two polymers. Film 80/20 composition shows an apparent miscibility to the detection limit of the optical microscope. However upon annealing at $122{ }^{\circ} \mathrm{C}$ for $4 \mathrm{~h}$, phase separation with interconnected PChMA domains is activated.

Fig. 3 shows second run $T_{\mathrm{g}}$ 's as a function of blend composition of PChMA-Py in both THF and $\mathrm{Cl}_{3} \mathrm{H}$ casting solvents. Two $T_{\mathrm{g}}$ 's were observed over all composition, nevertheless they do not correspond to those of the individual components, above all to the PVAc-rich samples. $T_{\mathrm{g}}$ outside the value defined by the homopolymer PChMA $\left(T_{\mathrm{g}}>82^{\circ} \mathrm{C}\right)$ for both $\mathrm{THF}$ and $\mathrm{Cl}_{3} \mathrm{CH}$ cast film, is observed, suggesting that PChMA is more rigid in segregates microphases than in bulk, whereas PVAc is slightly more flexible than in bulk $\left(T_{\mathrm{g}}<40{ }^{\circ} \mathrm{C}\right)$ for $\mathrm{Cl}_{3} \mathrm{CH}$ cast samples.

This outside increases on $T_{\mathrm{g}}$ of PChMA is strange due to polymer-polymer poor attractive interaction in the polymer blend here studied [18]. However, the behaviour in ternary polymer-polymer-solvent system may be different [19] and some interactions could have been developed during casting.

On the other hand, the intermolecular interactions are influenced by the morphology of the segregated domains. When the phase separation is matrix-domain (20/80 and 50/ 50 from cast-THF and $\mathrm{Cl}_{3} \mathrm{CH}$, see Figs. 1 and 2), and the matrix is constituted by the polymer more flexible, it allows to the rigid polymer becomes packed in microphases in a more compact form than the homopolymer. A growth in intermolecular interaction will now lead to a growth in $T_{\mathrm{g}}$ of the rigid polymer (PChMA) in the presence of the flexible one (PVAc) [15].

\section{References}

[1] D.R. Paul, S. Newman, Polymer Blends, Academic Press, Florida, 1974.

[2] G.D. Merfeld, D.R. Paul, in: D.R. Paul, C.B. Bucknall (Eds.), Polymer Blend, vol. 1, Wiley, New York, 2000, Chapter 3.

[3] E. Helfand, A.M. Sapse, J. Chem. Phys. 62 (1975) 1327. 
[4] B. Djermouni, H.J. Ache, Macromolecules 13 (1980) 168.

[5] J.I. Goldstein, D.E. Newbury, P.E. Chelín, D.C. Coy, C. Fiori, Lifshin, Scanning Electrón Microscopy and X-ray MICROANALYSES, Plenum Press, New York, 1978.

[6] K. Søndergaard, J. Lyngaae, Polymer 37 (1986) 509.

[7] M.A. Winnik (Ed.), Photophysical and Photochemical Tools in Polymer Science: Conformation, Dynamic and Morphology, NATO ASI Series, vol. 182, The Netherlands, 1986.

[8] E.G. Granados, J. González-Benito, J. Baselga, D. Dibbern-Brunelli, T.D.Z. Atvars, I. Esteban, I.F. Piérola, J. Appl. Polym. Sci. 80 (2001) 949.

[9] D. Dibbern-Brunelli, T.D.Z. Atvars, J. Appl. Polym. Sci. 55 (1995) 889.

[10] H. Morawetz, J. Polym. Sci. 37 (1999) 1725.

[11] T.D.Z. Atvars, I. Esteban, B. Illera, B. Serrano, M.R. Vigil, I.F. Piérola, J. Lumin. 72-74 (1997) 467.

[12] J.P.S. Farinha, O. Vorobyoya, M.A. Winnik, Macromolecules 33 (2000) 5863.

[13] B. Serrano, J. Baselga, J. Bravo, F. Mikes, L. Sesé, I. Esteban, I.F. Piérola, J. Fluoresc. 10 (2000) 135

[14] B. Serrano, J. Baselga, I. Esteban, L. Sesé, I.F. Piérola, J. Appl. Polym. Sci. (2003) in press.

[15] V.A. Bershtein, V.M. Egorov, Differential Scanning Calorimetric of Polymer, Ellis Horwood, New York, 1994, Chapter 3.

[16] O. Olabisi, L.M. Robeson, M.T. Shaw, Polymer-Polymer Miscibility, Academic Press, New York, 1979.

[17] R.A. Hutchinson, S. Beuermann, D.A. Paquet, J.H. McMinn, Macromolecules 31 (1998) 1542.

[18] J.M. O'Reilly, R.A. Mosher, Macromolecules 14 (1981) 602.

[19] H.Y. Yang, P.P. Zhu, F. Ren, Y.Y. Wang, T. Zhang, Eur. Polym. J. 36 (2000) 21 